\title{
High strength concrete small hollow blocks made with rock chips as aggregates
}

\author{
Zhang Yongquan ${ }^{a}$, Yuan Jie ${ }^{b}$, Ge Yong ${ }^{c}$
}

\author{
School of Transportation Science and Engineering, Harbin Institute of Technology, Harbin 150090, \\ China \\ a zyqzygzs@126.com, b hityuanj@163.com, c hitbm@163.com
}

\begin{abstract}
Keywords: rock chips; high strength concrete small hollow blocks; fractal dimension; curing methods; shrinkage
\end{abstract}

\begin{abstract}
It is more and more general of using industrial solid waste as the aggregates in construction materials for non-structural applications. But because of the developments and applications of reinforced blocks masonry structure in the modern masonry structure, especially in the mid-high and high storey buildings, there will be a growing interest of using industrial solid waste to produce high strength concrete small hollow blocks for structural applications. This experiment by mixing the different proportions of rock chips within the range of $30-70 \%$ as the replacement for sand prepared high strength concrete small hollow blocks which the compressive grade is MU 15.0, the influence of aggregates grading on the compressive strength of high strength concrete small hollow blocks was investigated at the same water/cement $(\mathrm{w} / \mathrm{c})$ ratio $(0.45)$. In addition, the influence of the different curing methods on the compressive strength and shrinkage of high strength concrete small hollow blocks were also investigated, test results showed that high strength concrete small hollow blocks under the curing method which is the one-time pouring the ample amount of water, covered and sealed with plastic sheeting, the compressive strength had a better development, and the total shrinkage was larger than others.
\end{abstract}

\section{Introduction}

There will be a big development of Chinese housing construction in the future for a long period of time, which requires the construction industry must be according with sustainable development strategy, break the routine, develop the new wall materials [1]. Since "Eleventh Five-Year Plan", the new building materials based on the building energy efficiency had a rapid development, the using of which played a "four of a green" objectives in the building structure [2]. The foreign researchers $[3,4]$ studied that the replacement of coarse and fine natural aggregates by recycled aggregates at the suitable levels had little effect on the compressive strength of the blocks, based on the laboratory work, factory trials showed that there were no practical problems with the use of recycled demolition aggregate in the manufacture of building blocks. Some domestic scholars [5-7] using industrial waste such as iron-tailings, steel slag, and gangue prepared the MU10.0 load-bearing concrete hollow blocks, which resulted in a good economic and social benefits. However, the study of preparing high strength concrete small hollow blocks more than MU15.0 and 45 percent hole rate with industrial waste is more lesser.

Concrete small hollow blocks are non-sintering prepared with a certain percentage gelled materials and aggregates by mechanical forming and curing, which performances are influenced by the changes of ambient temperature and humidity. In the former block masonry structure applications, the practical strength less than the design strength resulted the problems of missing edge off angle and cracks in walls, which even seriously affected the quality of the engineering, so how to ensure the excellent performances of concrete small hollow blocks become one of the widespread concerned problems [8]. Sunil Kumar [9] studied the influence of type of curing on the increase in strength and hardening of the blocks with time, and the results showed that the hot water curing leads to a greater degree of hardening, and higher strength, earlier compared to ordinary water curing. F.O. Ogunye [10] tested two different soil block samples, stablished with cement, lime and lime-gypsum at varying proportions and cured at both room temperature (RT) and elevated 
temperature (ET), showed that the mass loss of the blocks cured at elevated temperature was smaller than the blocks cured at room temperature in the simulated rainfall. Ismail Demir [11] reported that optimal strength-thermal conductivity combination was obtained by the usage of silica fume and expanded perlite together. Improved strength properties were obtained by using hydrothermal curing conditions and super-plasticizer addition. Therefore, the curing methods are more important for the performance of concrete small hollow blocks.

This paper presents a recent study at the Harbin Institute of Technology on the feasibility of using rock chips replaced natural sand as aggregates for high strength concrete small hollow blocks. The main objective of this study was to develop the appropriate technologies for the production of high strength concrete small hollow blocks which hold better qualities.

\section{Experimental Section}

\subsection{Materials}

\subsubsection{Cement}

In this study, a Chinese standard 42.5 ordinary Portland cement was used and the corresponding properties are shown in Table 1.

Table 1 Chemical analysis of cement

\begin{tabular}{cccccccc}
\hline $\mathrm{CaO}$ & $\mathrm{SiO}_{2}$ & $\mathrm{Al}_{2} \mathrm{O}_{3}$ & $\mathrm{Fe}_{2} \mathrm{O}_{3}$ & $\mathrm{Na}_{2} \mathrm{O}$ & $\mathrm{K}_{2} \mathrm{O}$ & $\mathrm{MgO}$ & $\mathrm{SO}_{3}$ \\
\hline 57.4 & 20.3 & 5.2 & 3.3 & 0.16 & 0.42 & 1.9 & 4.24 \\
\hline
\end{tabular}

\subsubsection{Rock chips}

The rock chips were obtained from a quarry named Heng chang in A'Cheng, Harbin. The waste in the progress of gravel production is rock chips, which have the same chemical composition with parent rock. The particle size of rock chips is generally bellow $4.75 \mathrm{~mm}$, usually there is a certain content powder which particle size is less than $0.15 \mathrm{~mm}$. The technical indicators of rock chips such as the physical properties varied greatly because of the different production technology, the range of fineness modulus is between 1.7 and 4.6 , apparent density between $2.64 \mathrm{~kg} / \mathrm{m}^{3}$ and $2.84 \mathrm{~kg} / \mathrm{m}^{3}$, packing density between $1.38 \mathrm{~kg} / \mathrm{m}^{3}$ and $1.59 \mathrm{~kg} / \mathrm{m}^{3}$, porosity between $42 \%$ and $48 \%$. Therefore, the physical properties of rock chips are similar with natural sand, it is more suitable material which can replace natural sands in the practical engineering applications. The properties of the rock chips were tested according to ASTM C136 and the results are presented in Table 2 and Table 3.

Table 2 The properties of the rock chips and river sand

\begin{tabular}{lccccc}
\hline & $\begin{array}{c}\text { Fineness } \\
\text { Modulus }\end{array}$ & $\begin{array}{c}\text { Silt Content } \\
(\%)\end{array}$ & $\begin{array}{c}\text { Voidage } \\
(\%)\end{array}$ & $\begin{array}{c}\text { Gradation } \\
\text { interval }\end{array}$ & $\begin{array}{c}\text { Apparent Density } \\
\left(\mathrm{kg} / \mathrm{m}^{3}\right)\end{array}$ \\
\hline River sand & 2.91 & 1.00 & 32.0 & II & 2580 \\
Rock chips & 3.50 & 5.0 & 32.5 & I & 2650 \\
\hline
\end{tabular}

Table 3 Chemical analysis of stone powder

\begin{tabular}{cccccccc}
\hline $\mathrm{SiO}_{2}$ & $\mathrm{Fe}_{2} \mathrm{O}_{3}$ & $\mathrm{Al}_{2} \mathrm{O}_{3}$ & $\mathrm{CaO}$ & $\mathrm{Na}_{2} \mathrm{O}$ & $\mathrm{K}_{2} \mathrm{O}$ & $\mathrm{MgO}$ & $\mathrm{SO}_{3}$ \\
\hline 57.3 & 6.1 & 14.6 & 5.4 & 6.3 & 2.9 & 1.9 & 0.3 \\
\hline
\end{tabular}

\subsubsection{River sand}

River sand with a maximum size of $4.75 \mathrm{~mm}$ and a fineness modulus of 2.91 was used the fine natural aggregates in this study. The properties of the sand were tested according to ASTM C136 and the results are presented in Table 3.

\subsubsection{Crushed stone}

Crushed stone obtained from the same quarry as rock chips was used as the coarse aggregate. 
2.2 Mix proportions of high strength concrete small hollow blocks

Table 4 Mix proportions of high strength concrete small hollow blocks

\begin{tabular}{cccccc}
\hline \multirow{2}{*}{ Notation } & \multirow{2}{*}{ Cement } & \multirow{2}{*}{ Water } & \multirow{2}{*}{ Coarse aggregate } & \multicolumn{2}{c}{ Fine aggregate } \\
\cline { 5 - 6 } & & & & Rock chips & Sand \\
\hline RC50-1 & 360 & 162 & 914 & 274 & 640 \\
RC55-2 & 360 & 162 & 823 & 402 & 603 \\
RC60-3 & 360 & 162 & 731 & 549 & 548 \\
RC65-4 & 360 & 162 & 640 & 713 & 475 \\
RC70-5 & 360 & 162 & 548 & 896 & 384 \\
BMP & 340 & 153 & 667 & 868 & 372 \\
\hline
\end{tabular}

\subsection{Preparation of the blocks specimens}

The high strength concrete small hollow blocks were fabricated in steel moulds with internal dimensions of $390 \mathrm{~mm}$ in length, $190 \mathrm{~mm}$ in width, $190 \mathrm{~mm}$ in depth. Initially, cement, coarse and fine aggregates, were mixed in a pan mixer for approximately $3 \mathrm{~min}$. After mixing, water was incrementally added to the mixtures until the desired moisture content for these dry mixtures was obtained. For fabrication of block specimens, only a small amount of water was required to prepare a cohesive mix but with zero slump (non-workability, which simulated the actual industrial production process of concrete blocks). The molding process was high frequency vibration and squeezing compacting, molding time was controlled at about $4 \mathrm{~s}$. The fabricated block specimens were putted on the steel layer boards, left at room temperature of $20 \pm 5^{\circ} \mathrm{C}$ and $75 \pm 5$ relative humidity $(\mathrm{RH})$ for $4 \mathrm{~h}$. The block specimens were then putted into the steam curing kiln and cured at a specific way which is warming up to $70^{\circ} \mathrm{C}$ within $3 \mathrm{~h}$, then thermostating $3 \mathrm{~h}$, at last cooling for $6 \mathrm{~h}$.

\subsection{Curing methods}

High strength concrete small hollow blocks were cured in the storage yard after carried out steam curing kiln. According to the climatic characteristics of Harbin in May, this study designed the following three kinds of curing method as shown in Table 5.In order to better evaluate the three kinds of curing method, laboratory standard curing method was taken as the reference. The mix proportion of high strength concrete small hollow blocks was shown in Table 4 which number was BMP.

Table 5 Curing methods in the storage yard

\begin{tabular}{cc}
\hline Number & Specific details of curing method \\
\hline A & covered and sealed with plastic sheeting, one-time pouring the ample of water \\
B & not covered with plastic sheeting, one-time pouring some water every day \\
C & not covered with plastic sheeting, one-time pouring some water every seven days \\
\hline
\end{tabular}

\subsection{Test methods}

\subsubsection{Grading fractal dimension}

Xie Heping [12] took a statistical analysis about the distribution of the particle size of broken rock, which has the statistical significance of the fractal behavior and self-similarity. The equations were obtained as follows.

$$
\begin{gathered}
M(r) / M=(R / \sigma)^{\alpha} \\
D_{J}=3-\alpha
\end{gathered}
$$

Where $M$ is the total mass of aggregates, $M(r)$ is the cumulative sieve of which size, and $\mathrm{D}_{J}$ is the fractal dimension, which is the measure of the complexity of distribution of the particle size. According to the solving model of the two equations calculated the grading fractal dimension using Matlab software. 


\subsubsection{Compressive strength}

The compressive strength was determined by using a universal testing machine with a maximum capacity of $2000 \mathrm{kN}$. The loading rate of $320 \mathrm{kN} / \mathrm{min}$ was applied to the nominal area of the block specimen. Prior to the loading test, the compressive surfaces of the block specimens were made level by cement mortar which compressive strength is $28.6 \mathrm{MPa}$. Three samples were tested for each mix proportion and curing method.

\subsubsection{Shrinkage}

After the steam curing, the two length measuring heads were fixed on half-height of any a surface of the block specimens along the horizontal direction by Epoxy resin, the initial length between them is $250 \mathrm{~mm}$. The tool of measuring length in this paper named hand-held strain gauge, which accuracy of measurement is $0.001 \mathrm{~mm}$. Then the block specimens were taken into storage yard under three curing methods showed in table until further measurement at 1st, 3rd, 7th, 14th, 28th, 45th day. Each value represents the average of three measurements.

\section{Results and Discussion}

3.1 Grading fractal dimension

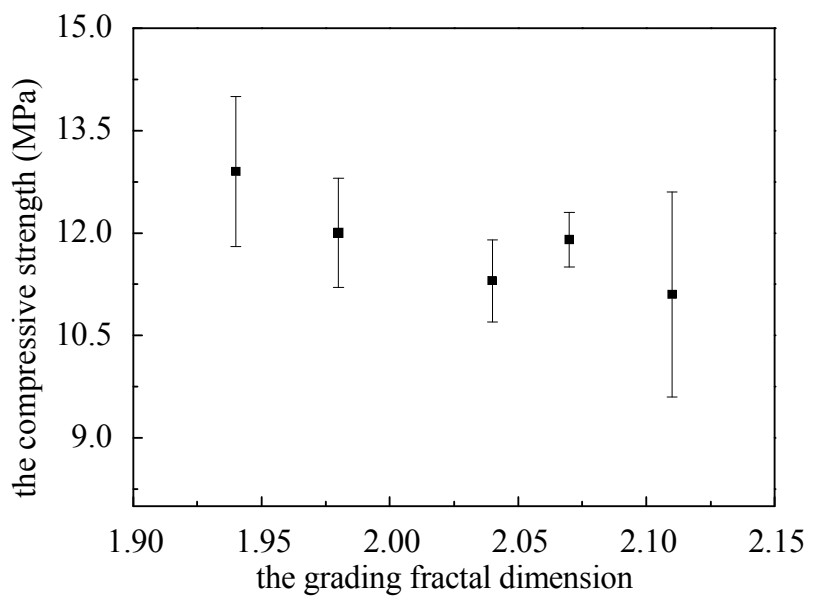

Fig 1 The influence of the grading dimension on the compressive strength of the blocks

It can be seen from the Fig 1 that when the grading dimension was between 1.94 and 2.11, the compressive strength of the blocks is between 11.1 and 12.9. With the increase of the grading fractal dimension the discreteness of values became larger, but in this experiment, the change of which was not too large, the compressive strength of high strength concrete small hollow blocks meet the design requirements. The grading fractal dimension expressed a range of grade, so any range of the grading fractal dimension is behalf of some a range of grade. In this paper, there is a certain practical significance that setting the grading fractal dimension to control the compressive strength of high strength concrete small hollow blocks.

\subsection{Compressive strength}

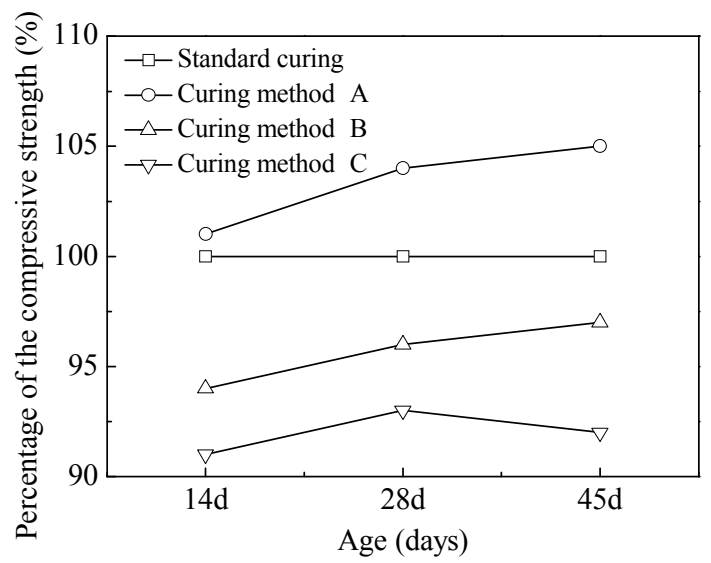

Fig 2 The influence of curing methods on the compressive strength of the blocks 
It can be seen from the Fig 2 that the compressive strength of high strength concrete small hollow blocks at the age of 28 days and 45 days under the curing method A were bigger than two other curing methods, respectively was 108.3 percent and 107.1 percent of the blocks under the curing method B, was 110.6 percent and 112.9 percent of the blocks under the curing method C. With the increase of age the compressive strength of high strength concrete small hollow blocks were growing under the two curing methods A and B, the rate of growing were was more slowly, but the compressive of the blocks at the age of 45 days were smaller than the 28 days under the curing method C. After poured the ample amount of water, then covered and sealed with the plastic sheeting, the temperature and relative humidity of the closed system was respectively more than $50^{\circ} \mathrm{C}$ and $95 \%$, which is beneficial to the accelerating of hydration, so the compressive strength of the blocks under this curing method was growing faster. On the contrary, the compressive strength of the blocks was smaller in the open system, especially the curing method C. Poured one time every seven days, the relative humidity of outdoor climate is below $80 \%$, so moisture lost too fast and there was no extra water supplied except the rain water, thereby the compressive strength of the blocks was growing slowly and even came up the negative growth because of the lower relative moisture content.

In another perspective, not covered the plastic sheeting, the compressive strength of high strength concrete small hollow blocks was seriously affected by the climate change, which will also take bad effects on the quality of high strength concrete small hollow blocks, so if high strength concrete small hollow blocks are not cured effectively, there will be asymmetrical in the compressive strength when the blocks are applied in walls at the age of 28 days.

3.3 Shrinkage

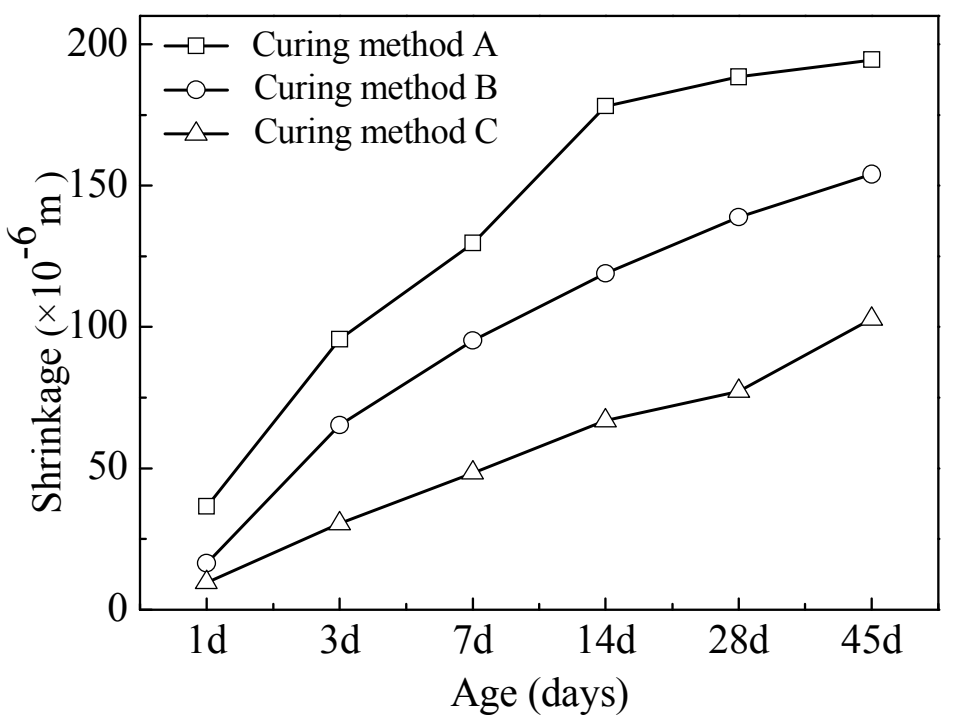

Fig 3 The influence of curing methods on the shrinkage of the blocks

It can be seen from Fig 3, the total shrinkage of high strength rock chips concrete small hollow blocks was the biggest under the curing method A among the three curing methods, reached $194 \mu \mathrm{m} / \mathrm{mm}$. The total shrinkage of high strength rock chips concrete small hollow blocks under the curing method $C$ was the smallest, only reached $103 \mu \mathrm{m} / \mathrm{mm}$, and the total shrinkage of high strength rock chips concrete small hollow blocks under the curing method B was between them, reached $154 \mu \mathrm{m} / \mathrm{mm}$. The total shrinkage of the blocks under the curing method A at the age of 14 days was larger than the total shrinkage of the blocks under the curing methods $\mathrm{B}$ and $\mathrm{C}$ at the age of 45 days. Under the three curing methods, the main influencing factors of the total shrinkage were relative to hydration, the drying shrinkage of hardened cement pastes and moisture loss or migration. Continued hydration played a major role on the increasing shrinkage under the curing method A, because of the degree of hydration became more and more bigger, which directly resulted in the volume change of concrete. But to the curing method $\mathrm{C}$, moisture loss or migration accounted for a major role, the loss or migration of moisture in pores of the cement gel could 
generate capillary tension which caused the shrinkage of concrete. The three factors corporately played roles on the shrinkage of the blocks under the curing method $\mathrm{B}$. As can be seen from the trend of the shrinkage, the slope of the curve A was changed at the age of 14 days, from which time to 45 days, the shrinkage of the blocks became slowly. The slopes of the curve B and C were almost unchanged in the 45 days, the shrinkage of them always increased, but the numerical value did not exceed the curve A. The strength of hardened cement pastes is rising with the hydration going on for the given concrete, so the absolute value of the shrinkage becomes smaller. When high strength concrete small hollow blocks under the curing methods $\mathrm{B}$ and $\mathrm{C}$ were applied in the construction buildings, there will be a bigger shrinkage because of temperature, humidity, stress and so on.

\section{Conclusions}

(1) Using the fractal dimension expressed the grading of aggregates is reasonable in some perspective. When the grading fractal dimensions were between 1.94 and 2.11, the compressive strength of high strength concrete small hollow blocks was larger, so by controlling the grading fractal dimension could control the quality of high strength concrete small hollow blocks.

(2) High strength concrete small hollow blocks under the curing method of one-time pouring ample amount of water, covered and sealed with plastic sheeting had larger shrinkage and bigger compressive strength. According to the theory, high strength concrete small hollow blocks at this curing method will not have any larger drying shrinkage applied in reinforced blocks masonry structure, and the quality of which can be better. So the problem of cracks in walls will be well solved from the new wall materials itself.

\section{References}

[1] Xu X, Xiao Y, Wu Q. Prospect and Measure of Construction Industry in China [J]. Journal of Shanghai Economic Management College, 2009, 4: 41-44.

[2] Wu H, Yang L, Li G. The development of new energy-saving building materials [J]. Shaanxi Architecture, 2008, 5: 1-4.

[3] C.S. Poon, S.C. Kou, L.Lam. Use of recycled aggregates in molded concrete bricks and blocks [J]. Construction and Building Materials, 2002(16): 281-289.

[4] Marios N. Soutsos, Kangkang Tang, Stephen G. Millard. Concrete building blocks made with recycled demolition aggregate [J]. Construction and Building Materials, 2011(25): 726-735.

[5] Deng Q, Li J. Concrete load-bearing small hollow blocks with iron tailings and slags [J]. China Construction Education, 2007.1: 47-49.

[6] Liu Y, Song S. Research on Steel Slag Concrete Small-Sized Hollow Block [J]. Journal of Beijing Institute of Civil Engineering and Architecture, 2007.3: 6-10.

[7] Xue C. Load-bearing blocks with gangue [J]. Fly Ash Comprehensive Utilization, 2002(2): 44-45.

[8] Lu C. Control of cracks in concrete hollow blocks wall [J]. Block-Brick-Tile, 2010, (2): 42-44.

[9] Sunil Kumar. A perspective study on fly ash-lime-gypsum bricks and hollow blocks for low cost housing development [J]. Construction and Building Materials, 2002, 16: 519-525.

[10]F. O. Ogunye, H. Boussabaine. Development of a rainfall test rig as an aid in soil block weathering assessment [J]. Construction and Building Materials, 2002(16):173-180.

[11]Ismail Demir, M. Serhat Baspinar. Effect of silica fume and expanded perlite addition on the technical properties of the fly ash-lime-gypsum mixture [J]. Construction and Building Materials, 2008, 22: 1299-1304.

[12]Xie H, Gao F. Fractal Fracture and Fragmentation in Rocks [J]. Journal of Seismology, 2003, 22(4): 1-9. 